\title{
Most severe risk factors in software development projects in Kuwait
}

\author{
Abdullah Alshehab ${ }^{1}$, Thalaya Alfozan ${ }^{2}$, Hesham gadelrab ${ }^{3}$ \\ ${ }^{1}$ Computing Department, College of Basic Education Public Authority of Applied Education and Training, Kuwait \\ ${ }^{2}$ Computer Science Department, College of Science Kuwait University, Kuwait \\ ${ }^{3}$ Phycology Department Kuwait University, Kuwait
}

\begin{tabular}{l} 
Article Info \\
\hline Article history: \\
Received Jun 7, 2020 \\
Revised Aug 6, 2020 \\
Accepted Aug 21, 2020 \\
\hline Keywords: \\
Risk factor \\
Risk management \\
Risk taxonomy \\
Software development project
\end{tabular}

Article Info

Article history:

Received Jun 7, 2020

Revised Aug 6, 2020

Keywords:

Risk factor

Risk taxonomy

Software development

\begin{abstract}
Software development projects are famous of high rate failure, this made an encouragement for researcher to investigate reasons of failure. However, literature covering under developed countries is uncommon. This research investigates the most severe risk factors in software development project in the country of Kuwait. A face-to-face questionnaire with 109 IT practitioners in Kuwait from government and private organizations was conducted. The findings reveal and identify risk factors that have a high impact on the budget, quality, and schedule. The aim of this study is to validate risk factor taxonomy through quantitative methods by experts in the field of IT. Another purpose of this research is to provide a comprehensive and updated review of risk factors from Kuwait to be presented for IT practitioners and researchers.
\end{abstract}

This is an open access article under the CC BY-SA license.

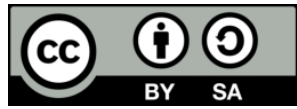

\section{Corresponding Author:}

Abdullah Alshehab

Computing Department

College of Basic Education Public Authority of Applied Education and Training, Kuwait

Email: Aj.alshehab@paaet.edu.kw

\section{INTRODUCTION}

According to one report [1] concentrating on USA and Europe organizations, its estimated that the number of software development projects that were on time, on budget, and on target is less than 36 percent leading to financial issues to the organizations. For example, one software development project in California, USA aimed to develop driver license and registration application with a budget of $\$ 160$ million. The project failed due to poor design and unclear objectives and other reasons relating to management of the project. Recent findings from National Audit Office, United Kingdom highlighted a report regarding failed Home Office e-borders scheme, that despite spending $£ 830$ million since April 2006, the project was not able to deliver its objectives [2].

Researchers and practitioners have been interested in the contextual effects of an IS project performance and the success of IS projects since many years ago [3,4]. Software development project do fail for one reason or the other, and the reasons are numerous and varied [5]. Software development projects are eminent with high failure rates remain a main concern to organizations and practitioners in the discipline for decades. This have encouraged and motivated researchers in the field to emphasis on project failure reasons. However, a) the continuous increase of complexity and uncertainty of software development projects and b) up-to-date technology and system development processes become major challenge [6]. Further, the literature holds studies, some studies developed a mathematical model that has the capability of mitigating the risk [7], other studies proposed system for better risk factor assessment [8], other studies proposed a risk management 
framework [9], other studies relating to identifying risk factors that could exists in software development project [10], however, studies focused on undeveloped countries are infrequent.

This study emphasis on investigating the most severe risk factors in Kuwait based on expert judgment in the discipline by applying quantitative measurements. The initial data used in this research extracted from a previous study developed earlier by the authors. Twenty-eight risk factors were collected, analyzed and evaluated from literature that was used in a face-to-face questionnaire with a sample of 109 IT practitioners from government and private organization [10].

The following research questions were addressed to IT experts in Kuwait:

a) What are the risk factors that are most likely to occur in Kuwait?

b) What is the severity of risk impact on the software project's a) quality, b) budget, and c) schedule?

c) What are the most severe risk factors that have the biggest impact in Kuwait?

The research focuses on measuring the severity of risk factors in an attempt to produce an updated risk factors taxonomy in Kuwait, adding to the body of knowledge more findings that could assess practitioners and contribute to delivering successful software development projects.

\section{LITERATURE REVIEW AND RELATED WORK}

[11] Suggest that risk identification could be the most important step in risk management approaches. [12] Argue that risk identification should be initiated at the commencement of a software project followed by a contingency plan based on the probability of occurrence and impact to mitigate or eliminate risk [12].

Some comparable research used quantitative methods, for example, [12] conducted an online survey with 86 participants to document data about past real projects, focusing on the risk factors that have a potential impact on the outcome of the projects. Further, the study was based on a collection of risk lists from previous research which was then examined by IT practitioners in the field and produced a ranked risk list. Another study designed to investigate the factors that contribute to the failure of IS projects in Jordanian companies [13]. Data was collected through a questionnaire given out by hand targeting IT practitioners in Jordanian companies. c projects and risk control techniques in Palestinian software development organizations. A structured questionnaire was sent to the software project manager and IT manager in Palestinian organizations and they produced a ranked list of software risk factors according to their importance and frequency.

One study investigating the reasons for the success and failure of IT projects in Saudi Arabia was conducted through an online structured questionnaire [10]. Three hundred and eight IT managers responded to this questionnaire. The authors, then, conducted semi structured interviews with eight project managers to validate the outcome of the questionnaire.

In a previous research conducted by the authors [10] an intense review of the literature from the period of 2000 to 2018. The purpose of the research was to identify risk factors in software development project available in the literature. Over 30 peer review papers in the field of information technology (IT) were reviewed [10,13-31]. The outcome of the research produced a list of 28 risk factors as shown in Table 1, that were validated by seven experts in the field of IT from Kuwait through focus group method.

\section{INSTRUMENT AND PARTICIPANTS}

The risk factor list in Table 1 was applied in a face-to-face interview with participants in the field of IT in Kuwait working in both government and private organizations [10]. The objective of the survey (see Appendix A) is an attempt to evaluate, validate and investigate the likelihood of occurrence and the severity of the impact of each risk on the project budget, schedule and quality. Each participant rated the impact of the risk through the use of a scale of four points: None, Low, Medium, or High.

109 participants working as IT experts from different organizations were interviewed in a face to face questionnaire. Demographic characteristics of the participants is presented in Table 2. About half of the participants are working in government entities. The positions of the participants were analysts $(31.2 \%)$, programmers $(21.1 \%)$, managers $(15.6 \%)$, and others $(32.1 \%)$. The majority of the participants have experience varying from 5 to 15 years in executing development projects, only $23 \%$ of them have more than 15 years of experience. As for project risk management methodology, $39 \%$ of the participants are using checklists, $36 \%$ are using brainstorming, $14.7 \%$ are using questionnaires, and the rest of the sample are using other methods. 
Table 1. Risk factor list with description

\section{Risk factor}

R1: Miscommunication

R2: Insufficient control of Project manager

R3: Team capability

R4: Poor understanding of user requirements

R5: Complexity of a project

R6: Unrealistic schedules

R7: Team Conflict

R8: Lack of top management commitment to project

R9: No planning or inadequate planning

R10: Changing scope/objectives

R11: Inadequate project management

$\mathrm{R} 12$ : Inadequate requirements

\section{R13: Lack of expertise}

R14: Resistance to change

\section{R15: Insufficient training}

R16: Lack of definition of roles and responsibilities

R17: Lack of knowledge

R18: Schedule pressure

R19: Lack of senior management technical leadership

R20: Resource insufficiency

\section{R21: Team Turnover}

R22: Choosing the wrong development strategy

R23: Lack of strategy alignment

R24: Poor quality deliverables

$\mathrm{R} 25$ : Lack of frozen requirements

R26: Technology shortfalls

R27: Budget not enough for maintenance activities

R28: Low quality of testing

\section{Description}

Many troubles may appear if there was miscommunication between customers, managers and developers. The developer may not understand the user actual needs, and the customers may under or overestimate their expectations

The project manager and/ or steering committee is not committed to solving problems and providing direction to the project team

Inability to complete work assigned owing to insufficient staff Expectations are mismatched with deliverable

Complexity risk is the uncertainty inherent in system complexity in terms of project difficulties. Characterized by immature technology, highly complex tasks, and high levels of technical complexity

The risk and uncertainty due to unrealistic schedule can impact the software project performance

Teamwork is also risky. The team as a whole may perform badly. Other team members can betray your trust by exploiting your contributions. A team culture can deteriorate into a toxic work environment

Lack of executive oversight, visible support and public endorsement as well as active policy intervention

Planning risk is the potential for a failure of project management to result in losses. It is typically documented as a risk when a project manager is instructed to alter or skip project management steps

When the organization changes or reorganizes partway through the project

The goal of project management is to produce a successful product or service Often this goal is hindered by the errors of omission as well as commission by management, project managers, team members and others associated with the projects

Not thoroughly defining the requirements of the new system before starting, consequently not understanding the true work effort, skill sets and technology required to complete the project

Reusability is not always the right choice, in such cases wherein the available expertise to maintain old components in order to reuse them is not available, it is actually a risk, because it may hinder the project and delay its progress

Recent research shows that end-users have a great impact on project success and project failure. Naturally, Human beings reject changes on the way they perform especially if these changes were imposed externally. This rejection deadly affects their acceptance to the new system negatively

Standard of work is poor owing to lack of ability, training, motivation and experience of staff

Risks from insufficient/inappropriate staffing imply the inability to allocate a skilled workforce to the project, regardless of availability

Lack of knowledge and/or experience in IS and/or business

The project is unable to realize its objectives owing to unrealistic restrictions placed on the projects schedule

Project management immaturity, lack of control, management style and poor implementation of methodology.

Sometimes, the available resources (i.e. people, tools and technologies) are not enough to complete the project. In other cases; the system cannot be implemented using the current available technology where the project involves the use of new technology. If these alike projects were posed it may threaten the project from being implemented successfully, wherein the developers may suffer from the technology change risks

In most organizations, experienced team member is looking for better job vacancies and leave their work if any was found. This factor threats any project in any of its phases.

This factor relates to failings as a direct result of inadequate requirements definition or poorly managed scope creep during the project lifecycle.

Strategy alignment is the process of bringing the actions of an organization's business divisions and staff members into line with the organization's planned objectives. So, Lack of strategic alignment is one of the major causes for organizations to fail

Risks that can affect to the quality of software are called as software quality risks

Requirements change because the needs of end-users change. The system is never moved into production because requirements are never finalized Information technology risk is the potential for technology shortfalls to result in losses. This includes the potential for project failures, operational problems and information security incidents

Budget risk is the potential for the estimates or assumptions built into a budget to turn out to be inaccurate. All budgets are based on future looking forecasts that typically involve some degree of uncertainty

Lack of testing during the system development project is one of the risk factors.

Lack of testing can impact the quality, reliability and cost of a product in software engineering projects 
Table 2. Sample descriptions according to organization type, position, experience, and management type

\begin{tabular}{|c|c|c|c|c|}
\hline \multicolumn{5}{|l|}{ Variable } \\
\hline Organization Type & \multicolumn{2}{|c|}{ Governmental } & \multicolumn{2}{|c|}{ Private } \\
\hline$\%$ & \multicolumn{2}{|c|}{$47.7 \%$} & \multicolumn{2}{|c|}{$52.3 \%$} \\
\hline Position & Analyst & Programmer & Project Manger & Other \\
\hline$\%$ & $31.2 \%$ & $21.1 \%$ & $15.6 \%$ & $32.1 \%$ \\
\hline Experience & \multicolumn{2}{|c|}{15 Years or less } & \multicolumn{2}{|c|}{ More than 15 Years } \\
\hline$\%$ & \multicolumn{2}{|c|}{$76.1 \%$} & \multicolumn{2}{|c|}{$23.9 \%$} \\
\hline Risk management approach & Brain Storming & Checklist & Questionnaire & Others \\
\hline$\%$ & $36.7 \%$ & $39.4 \%$ & $14.7 \%$ & $9.2 \%$ \\
\hline
\end{tabular}

\section{ANALYSIS AND DISCUSSION}

\subsection{Top rated risk factors according to likelihood of occurrence}

Table 3 presents the risk factors that were rated medium or high by at least $70 \%$ of the participants according to the likelihood of occurrence. Given a sample size of 109, and using the chi-square distribution, $66 \%$ would be significant at the .001 level [26]. We have used a more restrictive percentage of at least $70 \%$ of agreement among participants.

Table 3. Risk factors that were rated medium or high by at least $70 \%$ of the respondents with regard to the

\begin{tabular}{cccc}
\multicolumn{4}{c}{ likelihood of occurrence } \\
\hline Risk Factor & $\%$ Medium or High & 95\% Lower C.I. & 95\% Upper C.I. \\
\hline Complexity of a project & $80.60 \%$ & $72.20 \%$ & $87.30 \%$ \\
Team capability & $75.20 \%$ & $66.40 \%$ & $82.70 \%$ \\
Schedule pressure & $70.90 \%$ & $61.60 \%$ & $79.00 \%$ \\
Miscommunication & $70.50 \%$ & $61.30 \%$ & $78.60 \%$ \\
Lack of strategy alignment & $70.00 \%$ & $58.60 \%$ & $79.80 \%$ \\
\hline
\end{tabular}

Table 3 shows that five risk factors are likely to occur in software development projects. Complexity of the project, team capability, schedule pressure, miscommunication, and lack of strategy alignment may therefore be considered high-risk factors for a given project according to the experts' judgment.

\subsection{Differences of participants' responses for risk factors with regard to organization type}

In Table 4, significant differences among participants' responses in assessing risk factors were addressed. According to Table 3, the risk factors with the top likelihood of occurrence that were addressed by participants in government organization were "Miscommunication" and "Resistance to change". However, in private organizations another risk was addressed, which is "Resource insufficiency". Further, participants from private organizations selected "Low quality of testing" as having the most severe impact on software quality and "Insufficient control of project manager" having the most severe impact on the project schedule.

Table 4 Significant risk factors according to organization type, position, and experience

\begin{tabular}{ccccc}
\hline Risk Type* & Risk Factor & $\chi^{2}$ value $(\mathrm{df})$ & $p$ Value & In favor of** \\
\hline L & Miscommunication & $4.16(1)$ & .04 & $\mathrm{G}$ \\
L & Resistance to change & $3.85(1)$ & .05 & $\mathrm{G}$ \\
L & Resource insufficiency & $10.10(1)$ & .001 & $\mathrm{P}$ \\
Q & Low quality of testing & $6.05(1)$ & .01 & $\mathrm{P}$ \\
S & Unsufficient control of project manager & $4.41(1)$ & .04 & $\mathrm{P}$ \\
L & Unrealistic schedules & $15.29(3)$ & .002 & $\mathrm{~A}$ \\
L & Lack of top management commitment to project & $9.25(3)$ & .03 & $\mathrm{~A}$ \\
L & No planning or inadequate planning & $10.59(3)$ & .04 & $\mathrm{~A}$ \\
L & Inadequate project management & $11.55(3)$ & .009 & $\mathrm{~A}$ \\
L & Lack of definition of roles and responsibilities & $7.83(3)$ & .05 & $\mathrm{~A}$ \\
L & Choosing the wrong development strategy & $9.14(3)$ & .03 & $\mathrm{~A}$ \\
L & Poor quality deliverables & $8.08(3)$ & .04 & $\mathrm{~A} / \mathrm{PM}$ \\
Q & Miscommunication & $14.60(3)$ & .002 & $\mathrm{~A}$ \\
Q & Unrealistic schedules & $14.94(3)$ & .002 & $\mathrm{~A}$ \\
Q & Team Turnover & $11.40(3)$ & .01 & $\mathrm{~A}$ \\
B & Budget not enough for maintenance activities & $8.42(3)$ & .04 & $\mathrm{~A}$ \\
S & Complexity of a project & $8.26(3)$ & .04 & $\mathrm{PM}$ \\
L & Poor understanding of user requirements & $5.42(1)$ & .02 & $\mathrm{HE}$ \\
Q & Poor understanding of user requirements & $4.17(1)$ & .04 & $\mathrm{HE}$ \\
B & Changing scope/objectives & $5.47(1)$ & .02 & HE \\
B & Low quality of testing & $4.23(1)$ & .04 & HE \\
S & Poor understanding of user requirements & $5.74(1)$ & .02 & HE \\
\hline
\end{tabular}

$* \mathrm{~L}=$ Likelihood of risk occurrence, $\mathrm{Q}=$ Impact of risk on quality, $\mathrm{B}=$ Impact of risk on Budget, $\mathrm{S}=$ Impact of risk on schedule

** $\mathrm{G}=$ Governmental institution, $\mathrm{P}=$ Private institution, $\mathrm{A}=$ Analyst, $\mathrm{PM}=$ Project Manager, HE= More than 15 years of experience 
4.3. Differences of participants' responses for risk factors with regard to expert position and experience

As shown in Table 4, analysts had different assessments for risk factors compared to project managers and programmers. For example, compared to other positions "Analysts" believe that "Unrealistic schedules", "Lack of top management commitment to project" and "No planning or inadequate planning", "Inadequate project management", "Lack of definition of roles and responsibilities", "Choosing the wrong development strategy" have the highest likelihood of occurrence. Analyst and project managers agreed on the likelihood of occurrence of "Poor quality deliverables". On the Other hand, "Analysts" assessed "Miscommunication", "Unrealistic schedules", and "Team Turnover" to have an impact on quality more than other positions. However, "Project Managers" agreed that "Complexity of a project" has the highest impact on the schedule.

Participants with long experience (15 years or more) agreed that "Poor understanding of user requirements" has the highest likelihood of occurrence and has the highest impact on software quality and schedule. However, there is agreement on two risk factors, which are, "Changing scope/objectives" and "Low quality of testing", which have the highest impact on the project budget.

\subsection{Risk factors that have an impact on the quality, budget, and schedule of the project}

Table 5 presents the risk factors that were rated medium or high by at least $70 \%$ of the respondents with regard to impact on quality, budget, and schedule. As shown in Table 5, 13 risk factors have been identified according to their significant impact on quality, budget and schedule.

Table 5. Risk factors that were rated medium or high by at least $70 \%$ of the respondents with regard to impact on quality, budget, and schedule

\begin{tabular}{|c|c|c|c|c|c|c|c|c|c|}
\hline \multicolumn{10}{|c|}{ Quality Budget Schedule } \\
\hline & $\%$ & $95 \%$ & $95 \%$ & $\%$ & $95 \%$ & $95 \%$ & $\%$ & $95 \%$ & $95 \%$ \\
\hline Risk Factor & $\begin{array}{l}\text { Medium } \\
\text { or High }\end{array}$ & $\begin{array}{l}\text { Lower } \\
\text { C.I. }\end{array}$ & $\begin{array}{l}\text { Upper } \\
\text { C.I. }\end{array}$ & $\begin{array}{l}\text { Medium } \\
\text { or High }\end{array}$ & $\begin{array}{l}\text { Lower } \\
\text { C.I. }\end{array}$ & $\begin{array}{l}\text { Upper } \\
\text { C.I. }\end{array}$ & $\begin{array}{l}\text { Medium } \\
\text { or High }\end{array}$ & $\begin{array}{l}\text { Lower } \\
\text { C.I. }\end{array}$ & $\begin{array}{l}\text { Upper } \\
\text { C.I. }\end{array}$ \\
\hline Inadequate requirements & 70.20 & 60.90 & 78.30 & 75.20 & 66.40 & 82.70 & 74.00 & 65.00 & 81.70 \\
\hline $\begin{array}{l}\text { Lack of top management } \\
\text { commitment to project }\end{array}$ & 70.30 & 60.90 & 78.50 & 73.30 & 64.10 & 81.20 & 71.60 & 62.30 & 79.60 \\
\hline Changing scope/objectives & 71.30 & 62.00 & 79.40 & 75.20 & 66.20 & 82.90 & 85.00 & 64.90 & 82.10 \\
\hline $\begin{array}{l}\text { Poor understanding of user } \\
\text { requirements }\end{array}$ & 73.10 & 64.00 & 80.90 & 72.40 & 63.30 & 80.20 & 74.50 & 65.70 & 82.10 \\
\hline $\begin{array}{l}\text { Inadequate project } \\
\text { management }\end{array}$ & 73.70 & 64.50 & 81.60 & 75.80 & 66.70 & 83.40 & 72.00 & 62.70 & 80.10 \\
\hline $\begin{array}{l}\text { Choosing the wrong } \\
\text { development strategy }\end{array}$ & 73.70 & 64.50 & 81.60 & 75.00 & 65.90 & 82.70 & 74.20 & 64.90 & 82.10 \\
\hline $\begin{array}{l}\text { Insufficient control of Project } \\
\text { manager }\end{array}$ & 74.30 & 65.30 & 81.90 & 73.10 & 64.00 & 80.90 & 71.60 & 60.70 & 80.90 \\
\hline $\begin{array}{l}\text { Lack of definition of roles and } \\
\text { responsibilities }\end{array}$ & 75.00 & 65.90 & 82.70 & 70.30 & 60.90 & 78.50 & 77.00 & 68.10 & 84.40 \\
\hline Miscommunication & 78.10 & 69.50 & 85.20 & 76.60 & 68.00 & 83.90 & 80.00 & 71.60 & 86.80 \\
\hline $\begin{array}{l}\text { No planning or inadequate } \\
\text { planning }\end{array}$ & 80.40 & 71.90 & 87.20 & 72.50 & 63.30 & 80.50 & 75.50 & 66.50 & 83.00 \\
\hline Complexity of a project & 82.40 & 74.10 & 88.80 & 77.20 & 68.40 & 84.60 & 83.50 & 75.40 & 89.70 \\
\hline Resource insufficiency & 85.10 & 77.30 & 91.10 & 71.60 & 62.30 & 79.60 & 71.70 & 62.30 & 79.90 \\
\hline Lack of strategy alignment & 93.40 & 86.20 & 97.40 & 93.30 & 86.00 & 97.40 & 91.40 & 83.20 & 96.30 \\
\hline
\end{tabular}

\subsection{Risk factors according to organization type}

If you plan a software development project in the government sector in Kuwait, you need to take care of miscommunication and resistance to change. However, if your project is a private one, the risk factors that you should keep in mind in planning for such a project are resource insufficiency, low quality of testing, and insufficient control of the project manager. In general, risk factors that might threaten your project were identified, for example, lack of strategy alignment, and complexity of the project. If your concern is quality, then the risk factor that should be taken into consideration is resource insufficiency. If you focus more on the budget of the project, then plan to avoid inadequate requirements and project management. If the schedule commitment is your first priority, then plan to preclude complex projects, miscommunication, and change in the scope or objective of the project during implementation.

\subsection{Insight from the questionnaire}

Findings from the questionnaire reveal that most of the methodology used to identify risk factors was checklists (41\%) and brainstorming (38\%). As for project management methodology, the majority (42\%) uses the PMI framework. Lack of strategy alignment, miscommunication, and complexity of the project 
appeared to be the most salient risk factors in terms of likelihood of occurrence and their negative impact on quality, budget, and schedule of software development projects in Kuwait. Miscommunication and resistance to change were identified as higher risk factors in terms of likelihood in government projects; while resource insufficiency was identified as highly likely to occur in private projects. Low quality of testing, and insufficient control of the project manager have a more negative impact on quality and schedule respectively in private projects. Participants with longer experience have determined the following factors as high-risk: poor understanding of user requirements, changing scope/objectives, and a low quality of testing.

\section{LIMITATION}

Our study has some limitations. This study, like the mainstream of studies in the field, focuses only on identifying risks in software development projects, therefore we have used a survey as the tool for data collection. The data collection method was based on self-report responses, which are usually safe from systematic response bias and subjectivity. To deal with this limitation, we have used face-to-face interviews to collect data from experts individually. This method might increase the objectivity of the results, but using surveys may still limit this study. In addition, our resulting data was ordinal in nature, which might limit the available statistical analyses of the data. In the current study, we used percentages, standard error of percentages, confidence intervals around percentages, and chi-squares to analyze the data to match the ordinal nature of the data.

Another limitation could be the type of the organization, that is, practitioners that were interviewed from private sector seems to have more knowledge and hold advance training in managing project compared to government organization. This could be resolved by conducting research investigating on both government and private organization separately to reach more valid and/or accurate results. Further, the findings of the survey need to be validated by a) cross referencing the results with literature review and/or b) experts through qualitative research such as interview or case studies.

\section{CONCLUSION}

A face-to-face questionnaire was applied with 109 participants from Kuwait. The objective of the questionnaire was to investigate the risk factors that have the most likelihood of occurrence in software development projects in Kuwait along with the risk factors that have furthermost impact on quality, budget, and schedule.

One finding shown from the questionnaire is that practitioners from private sector tends to have more advance training and knowledge compared to colleagues from government sector. Other findings revealed that methodology used to identify risk factors was checklists. As for project management methodology, the majority (42\%) uses the PMI framework. Lack of strategy alignment appeared to be the most salient risk factor in terms of likelihood of occurrence and their negative impact on quality, budget, and schedule of software development projects in Kuwait. Further, top rated risk factors were Complexity of a project, team capability, schedule pressure, miscommunication, and lack of strategy alignment.

\section{REFERENCES}

[1] Standish report, 2014 (https://www.standishgroup.com/sample_research_files/CHAOSReport2014.pdf) [accessed 8 March 2020]

[2] BBC, 2015 Home Office criticised over £830m 'failed' borders scheme (https://www.bbc.com/news/uk-34988913) [Accessed 8 March 2020]

[3] Ahlan, A. R., Kartiwi, M., \& Sukmana, H. T, "Influences of the Input Factors Towards the Success of an Information System Project". TELKOMNIKA (Telecommunication Computing Electronics and Control), vol. 13, no. 2, pp. 686-693, 2015.

[4] Ahlan, A. R., \& Sukmana, H. T. "An alternative method for determining critical success factors of information system project”, TELKOMNIKA (Telecommunication Computing Electronics and Control), vol.12, no. 3, pp. 665674, September 2014.

[5] Dwivedi, Y.K., Wastell, D., Laumer, S., Henriksen, H.Z., Myers, M.D., Bunker, D., Elbanna, A., Ravishankar, M.N., \& Srivastava, S.C. "Research on Information Systems Failures and Successes: Status Update and Future Directions.” Information Systems Frontiers, vol. 17, no. 1, pp. 143-157, 2015.

[6] Baghizadeh, Z., Cecez-Kecmanovic, D., \& Schlagwein, D. "Review and critique of the information systems development project failure literature: An argument for exploring information systems development project distress", Journal of Information Technology, 2019. 0268396219832010.

[7] Firdose, S., \& Rao, L. M. "3LRM-3 layer risk mitigation modelling of ICT software development projects", International Journal of Electrical and Computer Engineering (IJECE), vol. 6, no. 1, pp. 349, 2016. 
[8] Firdose, S., \& Rao, L. M. "PORM: Predictive Optimization of Risk Management to Control Uncertainty Problems in Software Engineering", International Journal of Electrical \& Computer Engineering (IJECE) (2088-8708), vol. 8, 2018.

[9] Esteki, M., Gandomani, T. J., \& Farsani, H. K. "A risk management framework for distributed scrum using PRINCE2 methodology”, Bulletin of Electrical Engineering and Informatics (BEEI), vol. 9, no. 3, pp. 1299-1310, 2020.

[10] Alshehab, A., Alfozan, T., \& Gaderrab, H. "Risk Factors Taxonomy In Software Development Projects: Study From Kuwait”, Journal of Theoretical and Applied Information Technology, vol. 98, no. 9, 2020.

[11] Al-Shehab, A., Al-Fozan, T., Montibeller, G., Hughes, R. T., \& Winstanley, G. "Structuring risk in e-government development projects using a causal model", In ECIW2009-8th European Conference on Information Warfare and Security: ECIW2009, Academic Conferences Limited, p. 782009.

[12] Vahidnia, S., Tanrı̈vver, Ö. Ö., \&Askerzade, I. N. "An Evaluation Study of General Software Project Risk Based on Software Practitioners Experiences", International Journal of Computer Science \& Information Technology (IJCSIT), vol, 8. 2016.

[13] Sweis, R. "An investigation of failure in information systems projects: The case of Jordan", Journal of Management Research, vol. 7, no. 1, pp. 173-185, 2015.

[14] Jeong, E. J., Bae, J. H., \& Jeong, S. R. "Guidelines Aimed at Reducing the Risks of User Acceptance Delay in the Context of an IT Service Project Management Plan”, International Journal of Electrical \& Computer Engineering (2088-8708), vol. 5, no. 4, 2015.

[15] Bhardwaj, M., Rana, A., \& Sharma, N. K. "How software size influence productivity and project duration", International Journal of Electrical \& Computer Engineering (IJECE) (2088-8708), vol. 9, no. 3, 2019.

[16] Hajeer, S. A. I. "Critical Risk Factors for Information System (IS) Projects (IS) Projects between Sink and Swim", International Journal of Computer Science Engineering \& Technology, vol. 2, no. 6, 2012.

[17] Reed, A. H., \& Knight, L. V. "Project duration and risk factors on virtual projects", Journal of Computer Information Systems, vol. 54, no. 1, pp. 75-83, 2013.

[18] Shrivastava, S. V., \& Rathod, U. "A risk management framework for distributed agile projects", Information and software technology, vol. 85, pp. 1-15, 2017.

[19] Hijazi, H., Alqrainy, S., Muaidi, H., \& Khdour, T. "Identifying Causality Relation between Software Projects Risk Factors", IJSEIA, vol. 8, no. 2, pp. 51-58, 2014.

[20] Schmidt, R., Lyytinen, K., Keil, M., \& Cule, P. "Identifying software project risks: An international Delphi study" Journal of Management Information Systems, vol. 17, no. 4, pp. 5-36, 2001.

[21] Gholami, S. "Critical risk factors in outsourced support projects of IT", Journal of Management Research, vol. 4, no. 1, p. 1, 2012

[22] Hoodat, H., \& Rashidi, H. "Classification and analysis of risks in software engineering", World Academy of Science, Engineering and Technology, vol. 56, no. 32, pp. 446-452, 2009.

[23] Ziemba, E., \&Oblak, I. "Critical success factors for ERP systems implementation in public administration", In Proceedings of the Informing Science and Information Technology Education Conference. Informing Science Institute, pp. 1-19, 2013, July.

[24] Sherer, S. A., \& Alter, S. "Information systems risks and risk factors: are they mostly about information systems?", Communications of the Association for Information Systems, vol. 14, no. 1, p. 2, 2004.

[25] Ibrahim, R., Ayazi, E., Nasrmalek, S., \& Nakhat, S. "An investigation of critical failure factors in information technology projects”, Journal of Business and Management, vol. 10, no. 3, pp. 87-92, 2013.

[26] Kaur, B. P., \&Aggrawal, H. "Critical failure factors in information system: an exploratory review", Journal Of Global Research In Computer Science, vol. 4, no. 1, pp. 76-82, 2013.

[27] Sarigiannidis, L., \& Chatzoglou, P. D. "Quality vs risk: An investigation of their relationship in software development projects", International Journal of Project Management, vol. 32, no. 6, pp. 1073-1082, 2014.

[28] Zhou, L., Vasconcelos, A., \& Nunes, M. "Supporting decision making in risk management through an evidencebased information systems project risk checklist", Information management \& computer security, 2008.

[29] Ackermann, F., \& Alexander, J. "Researching complex projects: Using causal mapping to take a systems perspective", International Journal of Project Management, vol. 34, no. 6, pp. 891-901, 2016.

[30] Bloch, M., Blumberg, S., \&Laartz, J. "Delivering large-scale IT projects on time, on budget, and on value", Harvard Business Review, pp. 2-7, 2012.

[31] Alfaadel, F., Alawairdhi, M., \& Al-Zyoud, M. "Success and failure of IT projects: a study in Saudi Arabia", In Proceedings of the 11th WSEAS international conference on Applied Computer and Applied Computational Science, 2012, April.

\title{
Appendix A
}

\author{
Survey form \\ a. Type of organization \\ a. Industry \\ b. Academic \\ c. Government \\ d. Others (please specify)
}


b. Position
a. Programmer
b. Analyst
c. Project manager
d. Others (please specify)

c. Experience
a. 5-10 years
b. 10-15 years
c. 15-20 years
d. More than 20 years

d. In the last 3 IT projects you were involved in, were they:
a. All Successful
b. 1 successful 2 failure
c. 2 successful 1 failure
d. All failed

e. What is the Project Management methodology used in your organization
a. CMMI
b. Prince2
c. PMI framework
d. Others

f. What type of risk management methods you use in developing projects
a. Checklist
b. Brain Storming
c. Questionnaire
d. Other

Please put $[\sqrt{ }]$ mark against your opinion

\begin{tabular}{|c|c|c|c|c|c|}
\hline Risk factor & \multicolumn{5}{|c|}{ Mark } \\
\hline & $\begin{array}{c}\text { Likelihood of } \\
\text { occurrence }\end{array}$ & $\begin{array}{l}\text { Impact of risk } \\
\text { on Quality }\end{array}$ & $\begin{array}{l}\text { Impact of risk } \\
\text { on budget }\end{array}$ & \multicolumn{2}{|c|}{$\begin{array}{l}\text { Impact of risk } \\
\text { on Schedule }\end{array}$} \\
\hline \multirow[t]{4}{*}{ R1:Miscommunication } & None & & & & \\
\hline & Low & Low & Low & Low & \\
\hline & Med & Med & Med & Med & \\
\hline & High & High & High & High & \\
\hline \multirow{4}{*}{$\begin{array}{l}\text { R2: Insufficient control } \\
\text { of Project manager }\end{array}$} & None & & & & \\
\hline & Low & Low & Low & & \\
\hline & Med & Med & Med & & \\
\hline & High & High & High & & \\
\hline \multirow{4}{*}{ R3: Team capability } & None & & & & \\
\hline & Low & Low & Low & Low & \\
\hline & Med & Med & Med & Med & \\
\hline & High & High & High & High & \\
\hline \multirow{4}{*}{$\begin{array}{l}\text { R4:Poor understanding } \\
\text { of user requirements }\end{array}$} & None & & & & \\
\hline & Low & Low & Low & Low & \\
\hline & Med & Med & Med & Med & \\
\hline & High & High & High & High & \\
\hline \multirow{4}{*}{$\begin{array}{c}\text { R5:Complexity of a } \\
\text { project }\end{array}$} & None & & & & \\
\hline & Low & Low & Low & Low & \\
\hline & Med & Med & Med & Med & \\
\hline & High & High & High & High & \\
\hline \multirow{4}{*}{ R6: Unrealistic schedules } & None & & & & \\
\hline & Low & Low & Low & Low & \\
\hline & Med & Med & Med & Med & \\
\hline & High & High & High & High & \\
\hline \multirow{6}{*}{ R7:Team Conflict } & None & & & & \\
\hline & Low & Low & Low & Low & \\
\hline & Med & Med & Med & Med & \\
\hline & High & High & High & High & \\
\hline & Low & Low & Low & Low & \\
\hline & Med & Med & Med & Med & \\
\hline
\end{tabular}




\begin{tabular}{|c|c|c|c|c|}
\hline & High & High & High & High \\
\hline \multirow{4}{*}{$\begin{array}{c}\text { R8:Lack of top } \\
\text { management } \\
\text { commitment to project }\end{array}$} & None & & & \\
\hline & Low & Low & Low & Low \\
\hline & Med & Med & Med & Med \\
\hline & High & High & High & High \\
\hline \multirow{4}{*}{$\begin{array}{l}\text { R9:No planning or } \\
\text { inadequate planning }\end{array}$} & None & & & \\
\hline & Low & Low & Low & Low \\
\hline & Med & Med & Med & Med \\
\hline & High & High & High & High \\
\hline \multirow{4}{*}{$\begin{array}{l}\text { R10:Changing } \\
\text { scope/objectives }\end{array}$} & None & & & \\
\hline & Low & Low & Low & Low \\
\hline & Med & Med & Med & Med \\
\hline & High & High & High & High \\
\hline \multirow{4}{*}{$\begin{array}{l}\text { R11: Inadequate project } \\
\text { management }\end{array}$} & None & & & \\
\hline & Low & Low & Low & Low \\
\hline & Med & Med & Med & Med \\
\hline & High & High & High & High \\
\hline \multirow{4}{*}{$\begin{array}{l}\text { R12:Inadequate } \\
\text { requirements }\end{array}$} & None & & & \\
\hline & Low & Low & Low & Low \\
\hline & Med & Med & Med & Med \\
\hline & High & High & High & High \\
\hline \multirow{7}{*}{ R13: Lack of expertise } & None & & & \\
\hline & Low & Low & Low & Low \\
\hline & Med & Med & Med & Med \\
\hline & High & High & High & High \\
\hline & Low & Low & Low & Low \\
\hline & Med & Med & Med & Med \\
\hline & High & High & High & High \\
\hline \multirow{4}{*}{ R14:Resistance to change } & None & & & \\
\hline & Low & Low & Low & Low \\
\hline & Med & Med & Med & Med \\
\hline & High & High & High & High \\
\hline \multirow{7}{*}{ R15:Insufficient training } & None & & & \\
\hline & Low & Low & Low & Low \\
\hline & Med & Med & Med & Med \\
\hline & High & High & High & High \\
\hline & Low & Low & Low & Low \\
\hline & Med & Med & Med & Med \\
\hline & High & High & High & High \\
\hline \multirow{4}{*}{$\begin{array}{l}\text { R16:Lack of definition of } \\
\text { roles and responsibilities }\end{array}$} & None & & & \\
\hline & Low & Low & Low & Low \\
\hline & Med & Med & Med & Med \\
\hline & High & High & High & High \\
\hline \multirow{4}{*}{ R17:Lack of knowledge } & None & & & \\
\hline & Low & Low & Low & Low \\
\hline & Med & Med & Med & Med \\
\hline & High & High & High & High \\
\hline \multirow{4}{*}{ R18:Schedule pressure } & None & & & \\
\hline & Low & Low & Low & Low \\
\hline & Med & Med & Med & Med \\
\hline & High & High & High & High \\
\hline \multirow{4}{*}{$\begin{array}{l}\text { R19:Lack of senior } \\
\text { management technical } \\
\text { leadership }\end{array}$} & None & & & \\
\hline & Low & Low & Low & Low \\
\hline & Med & Med & Med & Med \\
\hline & High & High & High & High \\
\hline \multirow{4}{*}{$\begin{array}{l}\text { R20:Resource } \\
\text { insufficiency }\end{array}$} & None & & & \\
\hline & Low & Low & Low & Low \\
\hline & Med & Med & Med & Med \\
\hline & High & High & High & High \\
\hline \multirow{4}{*}{ R21: Team Turnover } & None & & & \\
\hline & Low & Low & Low & Low \\
\hline & Med & Med & Med & Med \\
\hline & High & High & High & High \\
\hline
\end{tabular}




\begin{tabular}{|c|c|c|c|c|}
\hline \multirow{4}{*}{$\begin{array}{l}\text { R22:Choosing the wrong } \\
\text { development strategy }\end{array}$} & None & & & \\
\hline & Low & Low & Low & Low \\
\hline & Med & Med & Med & Med \\
\hline & High & High & High & High \\
\hline \multirow{4}{*}{$\begin{array}{c}\text { R23: Lack of strategy } \\
\text { alignment }\end{array}$} & None & & & \\
\hline & Low & Low & Low & Low \\
\hline & Med & Med & Med & Med \\
\hline & High & High & High & High \\
\hline \multirow{4}{*}{ R24:Poor quality deliverables } & None & & & \\
\hline & Low & Low & Low & Low \\
\hline & Med & Med & Med & Med \\
\hline & High & High & High & High \\
\hline \multirow{4}{*}{$\begin{array}{l}\text { R25:Lack of frozen } \\
\text { requirements }\end{array}$} & None & & & \\
\hline & Low & Low & Low & Low \\
\hline & Med & Med & Med & Med \\
\hline & High & High & High & High \\
\hline \multirow{4}{*}{$\begin{array}{l}\text { R26: Technology } \\
\text { shortfalls }\end{array}$} & None & & & \\
\hline & Low & Low & Low & Low \\
\hline & Med & Med & Med & Med \\
\hline & High & High & High & High \\
\hline \multirow{4}{*}{$\begin{array}{l}\text { R27:Budget not enough } \\
\text { for maintenance activities }\end{array}$} & None & & & \\
\hline & Low & Low & Low & Low \\
\hline & Med & Med & Med & Med \\
\hline & High & High & High & High \\
\hline \multirow{7}{*}{$\begin{array}{c}\text { R28:Low quality of } \\
\text { testing }\end{array}$} & None & & & \\
\hline & Low & Low & Low & Low \\
\hline & Med & Med & Med & Med \\
\hline & High & High & High & High \\
\hline & Low & Low & Low & Low \\
\hline & Med & Med & Med & Med \\
\hline & High & High & High & High \\
\hline
\end{tabular}

